\title{
COSTA RICA Y EL PROCESO DE PRODUCCIÓN DEL TLC: ESTRATEGIAS DE SOCIALIZACIÓN PROFESIONAL Y NUEVAS ÉLITES ESTATALES
}

\author{
COSTA RICA AND THE PRODUCTION PROCESS OF THE FTA: \\ PROFESSIONAL SOCIALIZATION STRATEGIES AND NEW STATE ELITES
}

Eugenia Molina Alfaro

\begin{abstract}
Resumen
A través de un estudio de caso sobre los principales integrantes del equipo costarricense negociador del TLC entre Centroamérica, República Dominicana y Estados Unidos, este artículo estudia cuáles fueron los mecanismos y las estrategias a través de las cuales ellos se constituyeron en actores influyentes de las políticas de desarrollo impulsadas en los últimos veinte años. Se argumenta sobre la socialización profesional anticipatoria como el mecanismo de adopción de ideas que les facilitó a su vez el ascenso profesional dentro de una nueva élite estatal. Se muestra cómo las estrategias de ascenso personal de estos individuos devienen en procesos de institucionalización de ciertas prácticas profesionales, al estilo de lo que Adler y Haas denominan una comunidad epistémica y que finalmente contribuyen en la producción de políticas y en la consolidación del nuevo rostro del Estado costarricense.
\end{abstract}

Palabras clave: Socialización profesional; elite estatal; comunidades epistémicas; tratado de libre comercio; políticas.

\begin{abstract}
Through a case study about the main members of the Costa Rican negotiator team of the Central America Free Trade Agreement (CAFTA) among Central America, Dominican Republic and the United States, this article addresses the question about what were the mechanisms and strategies through which they became influential actors of the development policies promoted in the last twenty years. The paper argues about the anticipatory professional socialization as the mechanism for adopting ideas that provided them, as well, the professional promotion inside a new State elite. It shows how the personal promotion strategies of those individuals causes the production of policies and processes that institutionalize certain professional practices, as Adler and Haas denominate, an epistemic community that contribute to the consolidation of the new face of the Costa Rican State.
\end{abstract}

Keywords: Professional socialization; state elite; epistemic communities; free trade agreement; policies. 


\section{Introducción}

La idea de firmar un Tratado de Libre Comercio entre Centroamérica y los Es-

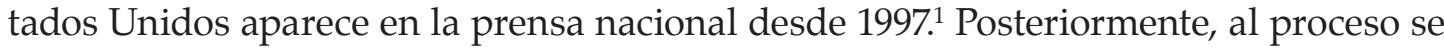
incorporó República Dominicana, lo cual dio origen al Dominican Republic-Central America Free Trade Agreement (DR-CAFTA, por sus siglas en inglés). En español, se conoce como Tratado de Libre Comercio entre República Dominicana, Centroamérica y Estados Unidos de América (TLC).

En Costa Rica, la propuesta de un TLC maduró hasta el año 2001, cuando surge uno de los proyectos de ley más polémicos (tal vez el más polémico de los últimos veinte años). En ese sentido, llama la atención que para su cabildeo y aprobación fue necesario que transcurrieran cuatro administraciones presidenciales.

Se considera que la negociación de este acuerdo fue muy rápida, puesto que se llevó a cabo en 14 meses, en tanto que el envío del proyecto al Parlamento tomó 17 meses. Si bien el expresidente Abel Pacheco impulsó el proyecto a inicios de su administración, y lo hizo con toda la energía de un gobierno entrante, a mitad de su periodo estaba dispuesto a desistir de este, debido a la fuerte oposición social que generó. La Tabla 1 expone un resumen de las etapas por las que pasó la tramitación del TLC.

Durante el lapso 1961-1991, el único tratado comercial preferencial firmado por Costa Rica fue el que dio origen al Mercado Común Centroamericano. Luego, entre 1994 y 2007, se firmaron nueve tratados comerciales (Alonso, 2009, 3).

Tabla 1

SÍNTESIS DE LA TRAYECTORIA DEL PROYECTO DEL TLC EN COSTA RICA

\begin{tabular}{ll}
\hline Fase y duración & Eventos importantes \\
\hline Cabildeo en Estados Unidos: & 1997: Propuesta inicial. \\
1994-2001 & Abril 2001: Estados Unidos lo anuncia.
\end{tabular}

Preparación: Septiembre 2001 a noviembre 2002
22 agosto 2002: Aprobación de TPA ${ }^{2}$ en Estados Unidos. Gestiones de Figueres Olsen y Rodríguez Echeverría a favor del TLC.

Talleres exploratorios de los países centroamericanos. Fin de una administración y comienzos de la siguiente.

Negociación 9 rondas de negociación para todos los países de Centroamérica y una más para Costa Rica.

Firma del tratado: Segundo año de la administración Pacheco de La Espriella. 


\begin{tabular}{|c|c|}
\hline Fase y duración & Eventos importantes \\
\hline & $\begin{array}{l}\text { Traducción del Tratado. } \\
\text { Firma de países centroamericanos el } 28 \text { de mayo } 2004 . \\
\text { Firma con República Dominicana el } 5 \text { de agosto } 2004 . \\
\text { En Costa Rica, división interna del equipo de gobierno: } \\
\text { renuncia el equipo económico y los negociadores. } \\
\text { Polémica nacional en torno a la constitucionalidad o no del } \\
\text { Proyecto de Ley. }\end{array}$ \\
\hline $\begin{array}{l}\text { Envío a la Asamblea Legislativa } \\
\text { Envío del proyecto: } 22 \text { de octubre } 2005 .\end{array}$ & $\begin{array}{l}\text { Presidente nombra Comisión de Notables para elaborar un } \\
\text { informe (del } 17 \text { de julio al } 16 \text { de septiembre del 2005). } \\
\text { Diputados presionan por el envío del proyecto. } \\
\text { Último año de gobierno de Pacheco. } \\
\text { Campaña electoral. }\end{array}$ \\
\hline 14 meses para el envío & $\begin{array}{l}\text { Óscar Arias hace campaña a favor del TLC. } \\
\text { Se habla de referendo. } \\
\text { Grupos favorables al proyecto refuerzan campaña. }\end{array}$ \\
\hline Discusión Legislativa & $\begin{array}{l}\text { Inicia discusión del proyecto. } \\
\text { Inician las audiencias. } \\
\text { Discusión sobre votación requerida. }\end{array}$ \\
\hline $\begin{array}{l}\text { Inicia en diciembre } 2005 \text {, se congela } \\
\text { hasta después de elecciones nacionales } \\
\text { ( } 6 \text { de abril 2006). }\end{array}$ & $\begin{array}{l}\text { Elecciones nacionales en } 2006 . \\
\text { TLC punto clave en agenda electoral. } \\
\text { Inicia polarización nacional. }\end{array}$ \\
\hline $\begin{array}{l}\text { Referendo } \\
12 \text { de abril } \\
\text { Convocatoria oficial el } 12 \text { de julio } \\
\text { (Decreto N. }{ }^{\circ} \text { 13-2007). }\end{array}$ & $\begin{array}{l}\text { Tribunal Supremo de Elecciones acoge solicitud de ciuda- } \\
\text { danos para convocar al referendo por iniciativa popular } \\
\text { (Resolución 790-E-2007). Al día siguiente, el presidente de } \\
\text { la República, Óscar Arias, anuncia que convocaría al refe- } \\
\text { rendo por Decreto Presidencial. } \\
\text { Marcha multitudinaria de oposición. } \\
\text { Memorando escrito por vicepresidente en julio para la } \\
\text { campaña del Sí provoca escándalo en septiembre. } \\
\text { Referéndum se realiza el } 7 \text { de octubre } 2007 . \\
\text { Resultado: A favor del SÍ, un } 51.7 \% \text {; frente a un } 48.3 \% \\
\text { del NO. }\end{array}$ \\
\hline
\end{tabular}

Fuente: Elaboración propia a partir de Molina (2009).

De manera que, en el periodo 2001-2007, ocurre la puesta en escena pública del acuerdo, su formulación y negociación; y el desenlace acontece el siete de octubre de ese mismo año, con la realización de un referendo que finaliza la etapa de aprobación. Este artículo retoma partes centrales de la tesis doctoral de la autora. El abordaje metodológico se hizo a través de un estudio de caso cuya unidad de análisis es el 
equipo negociador costarricense del TLC con Estados Unidos y su trayectoria laboral. Se trata de un estudio de caso cualitativo, el cual buscó conocer a profundidad las estrategias de socialización profesional de este equipo. El caso es relevante no solo por el interés histórico que suscitó este acuerdo comercial, sino también por la importancia que supone investigar sobre el papel que juegan las ideas y las estrategias de socialización profesional en la transformación del Estado, la producción de nuevas elites y las políticas de desarrollo en contextos neoliberales.

El caso seleccionado no sigue la lógica de la representatividad estadística, sino analítica (Coller, 2000, 34), pues el objeto de estudio constituye una situación óptima para poner a prueba una serie de afirmaciones teóricas. En ese sentido, no se trata de un caso excepcional ni típico, sino ilustrativo de situaciones en las cuales la socialización de ideas puede jugar un rol importante en las políticas públicas.

\section{Las estrategias de socialización y formación profesional de los negociadores}

Para entender la dinámica de las nuevas generaciones profesionales y el surgimiento de nuevos actores y saberes estatales en los contextos de cambio reciente, es importante tener en cuenta una serie de foros e instituciones internacionales que se convirtieron en espacios de socialización profesional, donde se elaboraron, compartieron y difundieron visiones sobre el desarrollo. En ese sentido, el trabajo de Molina (2009) identificó las instituciones, los grupos y los individuos que le sirvieron de referencia, tanto nacional como internacionalmente, al equipo negociador del TLC.

Dos instituciones internacionales y dos regionales jugaron un papel clave para la socialización de ideas de los negociadores costarricenses. En el campo internacional, se identifican la Organización Mundial del Comercio (OMC) y la Oficina del Representante Comercial de los Estados Unidos. Mientras que, en el área regional, se encuentran el Instituto Centroamericano de Administración de Empresas (INCAE) y la Academia de Centroamérica (Molina, 2009).

Con diferentes matices, todas estas instituciones de referencia comparten un esquema de pensamiento que surgió al calor del contexto internacional de cambio de fines de los años setenta. Contexto en el cual estas instituciones son producto y a la vez promueven una serie de valores que se importan y se exportan como categorías universales sobre el Estado, el comercio, la economía y el desarrollo.

El concepto de socialización tiende a estar asociado con un doble movimiento, discontinuo de acomodación y asimilación entre el individuo y el medio, el cual acaba, según Piaget, en la adolescencia, o bien, según otros autores, constituye un proceso permanente durante todo el ciclo de la vida (Dubar, 1991).

Enla sociología, Talcott Parsons, a partir de algunos aportes de Freud, Durkheim, Weber, Pareto, entre otros, intentó construir una teoría de la socialización dentro de su teoría general de la sociedad. Básicamente, le atribuye a ese proceso funciones 
decisivas, por ejemplo, la interiorización de normas y valores y la integración social. Según Parsons (1961), el proceso se realiza desde la primera infancia, por asimilación de los grandes modos de orientación de la familia de origen.

Esta investigación rescata dos dimensiones del concepto: el sistema de acción al cual refiere y la trayectoria individual. Es decir, se utiliza en la medida en que facilita aproximaciones que articulan dimensiones micro y macro, objetivas y subjetivas de lo social.

Ahora bien, preguntarse por los procesos y espacios de socialización en los cuales se forman y se construyen agentes sociales y políticas implica visualizar la socialización como un proceso que estructura y genera las prácticas, a partir del encuentro entre principios de percepción, pensamiento y acción en un campo de fuerzas sociales específicas (Bourdieu, 1980, 95). Esta manera de ver el proceso socializador y la adopción de valores constituye un avance, con respecto a las posiciones que ven la acción del agente como reacción mecánica inconsciente o como "elección intencional de un actor libre de cualquier condicionamiento". Tal postura permite explicar el hecho de que las disposiciones tiendan a ser durables y que se reproduzcan; $y$, más que racionales, los agentes tienden a ser razonables (Bourdieu, 1992, 85).

Siguiendo a Bourdieu, se podría decir que los negociadores del TLC se constituyen en agentes sociales influyentes a partir del encuentro entre sus trayectorias individuales y su encuentro con un "habitus neoliberal" de la época, gestado y reforzado en espacios nacionales e internacionales (Bourdieu, 1992, 89).

\section{De la alta inversión formativa a la socialización anticipatoria}

A diferencia de la ambición de Parsons por generar explicaciones de alcance universal, Robert Merton aportó una hipótesis para entender algunos mecanismos de relación, a través de los cuales se produce la adopción de valores y de creencias entre los individuos de un grupo. Estos mantienen un valor heurístico, si se ubican dentro de análisis empíricos sólidos (Dubar, 1991, 64).

En ese sentido, se retoma la distinción entre los conceptos de grupo de pertenencia, como grupo de origen; grupo de referencia, como grupo al que se aspira a pertenecer; y del concepto de frustración relativa, entendido como el juicio que se hace sobre una situación propia, a partir de la comparación con otro individuo o grupo. A partir de estos conceptos, el autor elaboró la hipótesis de la socialización anticipatoria. Dicho concepto explica el proceso por el cual un individuo interioriza los valores de un grupo que no es el suyo (grupo de referencia) y al cual desea pertenecer. Adopción que luego le facilita su adaptación.

Según Robert Merton (1967), se puede decir que los negociadores del TLC fueron parte de procesos de socialización anticipatoria. Ellos adoptaron, en forma temprana, no solo una serie de normas, valores y creencias, sino también determinados 
paradigmas sobre el comercio exterior. Lo anterior se hizo a partir de relaciones con agentes y funcionarios nacionales e internacionales influyentes; por lo tanto, este grupo se constituye, a través de su acceso al Estado, en parte de una élite transnacional.

La Tabla 2 muestra que los negociadores principales conforman un grupo que ha invertido tiempo y recursos en su formación, con lo cual, esta inversión se transforma en un capital profesional. ${ }^{3}$ La hoja de vida del exministro de Comercio Exterior, por ejemplo, dice lo siguiente: "Alberto Trejos obtuvo con honores el Ph.D. en Economía de la Universidad de Pennsylvania". Asimismo, en el caso de Federico Valerio, jefe de la mesa de negociación sobre servicios e inversión, se indica que cuenta con un título de doctorado y dos maestrías (una en Derecho Internacional y otra en Integración Económica), lo cual lo convierte en el más calificado de ese grupo.

Todos ellos realizaron sus estudios de bachillerato y licenciatura en Costa Rica, ${ }^{4}$ pero llevaron a cabo estudios de posgrado fuera del país, principalmente, en Inglaterra y en Estados Unidos. En general, las especializaciones se centran en áreas de la política económica, negociación y derecho internacional. Lo anterior tiene como espacio de intersección el comercio exterior.

Aparte de realizar estudios de maestría en el extranjero, ellos también recibieron cortas capacitaciones en temas más especializados. Tal es el caso de Anabel González, quien en dos ocasiones salió del país para adquirir conocimientos sobre negociaciones internacionales: en 1989, en el Centre for Applied Studies in International Negotiations en Ginebra (Suiza); y, en 1996, en la John F. Kennedy School of Government de la Harvard University, en Boston (EE. UU.) 
Tabla 2

SOCIALIZACIÓN PROFESIONAL DEL EQUIPO NEGOCIADOR

\begin{tabular}{|c|c|}
\hline Negociador & Recursos académicos \\
\hline Alberto Trejos & $\begin{array}{l}\text { Economista } \\
\text { M.A. University of Pennsylvania (Philadelphia, EE. UU.). } \\
\text { Ph.D. University of Pennsylvania. } \\
\text { Profesor en el Departamento de Economía de Northwestern University (Illinois, } \\
\text { EE. UU.), entre } 1993 \text { y } 1997 . \\
\text { Investigador visitante en el Institut d'Anàlisi Econòmica de Barcelona (España), } \\
\text { en el Federal Reserve Bank de Minneapolis y en el Center for Hemispheric } \\
\text { Policy (Miami, EE. UU.). } \\
\text { Profesor visitante en Fundaçao Getulio Vargas de Rio de Janeiro (Brasil), } \\
\text { University of Texas y University of Michigan (ambas de EE. UU.). } \\
\text { Profesor del Instituto Centroamericano de Administración de Empresas } \\
\text { (INCAE) desde 1998. Decano hasta el año 2002. } \\
\text { Profesor pleno del INCAE. } \\
\text { Director General del Centro Latinoamericano para la Competitividad y el } \\
\text { Desarrollo Sostenible. } \\
\text { Trabajo académico en la macroeconomía, economía internacional y economía } \\
\text { monetaria. } \\
\text { Ha obtenido financiamiento de parte de la Fulbright Foundation y la National } \\
\text { Science Foundation (ambas de EE. UU.). } \\
\text { Miembro de la Academia de Centroamérica (Costa Rica). } \\
\text { Número total de publicaciones } 13 \text { (hasta el 2009). }\end{array}$ \\
\hline Anabel González & $\begin{array}{l}\text { Licenciada en Derecho en la Facultad de Derecho de la Universidad de Costa } \\
\text { Rica, } 1986 . \\
\text { Maestría en Derecho del Comercio en Georgetown University Law Center en } \\
\text { Washington, } 1988 . \\
\text { Cursos sobre negociaciones internacionales en el Centre for Applied Studies in } \\
\text { International Negotiations en Ginebra, 1989, y en la John F. Kennedy School of } \\
\text { Government de la Harvard University (EE. UU.), } 1996 . \\
\text { Fundadora y profesora de la Cátedra de Comercio Exterior de la Universidad de } \\
\text { Costa Rica, de febrero } 1988 \text { a diciembre 1994. } \\
\text { Profesora de Derecho de la Contratación Privada, de febrero } 1988 \text { a julio } 1991 . \\
\text { Docente de la Facultad de Ciencias Políticas: Curso de Problemas Políticos de la } \\
\text { Economía Internacional, de agosto a diciembre 1990. } \\
\text { Profesora invitada en el INCAE 1992-1995. } \\
\text { Temas: comercio exterior, integración e inversión extranjera. } \\
\text { Miembro de la Academia de Centroamérica. } \\
\text { Investigadora asociada del Summit Center of the Americas, Florida } \\
\text { International University (Miami, EE. UU.). } \\
\text { Integrante del listado de panelistas del Capítulo de Solución de Controversias } \\
\text { del Acuerdo del Tratado de Libre Comercio entre Chile y México. } \\
\text { Integrante del listado de panelistas del Capítulo de Solución de Controversias } \\
\text { del Acuerdo de Complementación Económica entre Chile y Perú. }\end{array}$ \\
\hline
\end{tabular}




\begin{tabular}{|c|c|}
\hline Negociador & Recursos académicos \\
\hline Federico Valerio & $\begin{array}{l}\text { Licenciado en Derecho de la Universidad Autónoma de Centroamérica-Escuela } \\
\text { Libre de Derecho (Costa Rica). } \\
\text { Notario Público. } \\
\text { Graduado del Instituto del Servicio Exterior Manuel María Peralta (Ministerio } \\
\text { de Relaciones Exteriores de Costa Rica), } 1993 . \\
\text { Maestría Académica en Políticas del Mundo Económico de la London School of } \\
\text { Economics (Inglaterra). } \\
\text { Maestría en Relaciones Internacionales (Candidato) } \\
\text { Docente en la Maestría de Negocios Internacionales, Universidad de Costa Rica. } \\
\text { Curso Superior en Diplomacia. } \\
\text { Consultor internacional de organismos públicos y empresas privadas. } \\
\text { Diversas publicaciones. } \\
\text { Participación en conferencias y simposios internacionales. } \\
\text { Dominio del idioma inglés y conocimientos avanzados de francés e italiano. }\end{array}$ \\
\hline Roberto Echandi & $\begin{array}{l}\text { Licenciado en Derecho de la Universidad de Costa Rica, mayo } 1991 . \\
\text { Maestría en Derecho Internacional del Comercio, en la Escuela de Derecho de } \\
\text { la Universidad de Michigan (Ann Arbor, EE. UU.). } \\
\text { Doctorado de la Escuela de Derecho de la Universidad de Michigan. } \\
\text { Maestría en Estudios Latinoamericanos con énfasis en integración económica, } \\
\text { Universidad de Oxford (Inglaterra). } \\
\text { Estudios sobre procesos de negociación en la John F. Kennedy School of } \\
\text { Management de la Universidad de Harvard (Boston, EE. UU.). } \\
\text { Profesor Adjunto de la Facultad de Derecho de la Universidad de Georgetown, } \\
\text { Washington D.C. (EE. UU.). } \\
\text { Múltiples publicaciones internacionales. } \\
\text { Consultor de organismos internacionales en las Naciones Unidas, Banco } \\
\text { Interamericano de Desarrollo (BID), Organización de Estados Americanos } \\
\text { (OEA), Organisation for Economic Cooperation and Development (OECD). } \\
\text { Conferencista de política comercial y relaciones internacionales en toda } \\
\text { América, Europa y Asia. }\end{array}$ \\
\hline $\begin{array}{l}\text { Gabriela } \\
\text { Llobet }\end{array}$ & $\begin{array}{l}\text { Licenciada en Derecho de la Universidad de Costa Rica, mayo } 1995 . \\
\text { Maestría en Derecho Comercial Internacional de la Universidad de } \\
\text { Georgetown. } \\
\text { Maestría en Derecho Ambiental de la Universidad George Washington } \\
\text { (Washington D.C., EE. UU.). }\end{array}$ \\
\hline $\begin{array}{l}\text { Fernando } \\
\text { Ocampo }\end{array}$ & $\begin{array}{l}\text { Licenciado en Derecho de la Universidad de Costa Rica, agosto } 1993 . \\
\text { Maestría en Política Económica internacional, London School of Economics } \\
\text { (Inglaterra). } \\
\text { Abogado especialista en Derecho Público. } \\
\text { Consultor internacional en comercio exterior e integración comercial. }\end{array}$ \\
\hline
\end{tabular}




\begin{tabular}{ll}
\hline Negociador & Recursos académicos \\
\hline Amparo Pacheco & Licenciado en Economía de la Universidad de Costa Rica. \\
& Maestría en Política Económica con énfasis en Comercio Internacional, en la \\
& Universidad Nacional (Costa Rica). \\
& Investigadora por quince años en el Instituto de Investigaciones en Ciencias \\
& Económicas de la Universidad de Costa Rica. \\
& Profesora de la Universidad de Costa Rica y de la Universidad Estatal a \\
& Distancia (UNED - Costa Rica). \\
\hline Mariel Picado & Licenciada en Derecho, Universidad de Costa Rica. \\
& Maestría en Derecho (Estudios legales y Derecho Internacional), por el Institute \\
& of International Education (IIE) de Georgetown University (Washington D.C., \\
& EE. UU.). \\
\hline
\end{tabular}

Fuente: Elaboración propia a partir de las hojas de vida de cada negociador.

Nótese que el núcleo básico del equipo negociador se formó a partir de seis profesionales del derecho y dos economistas. El grupo ampliado, aunque incluye otras disciplinas profesionales, estuvo compuesto, en su mayoría también, por profesionales del derecho. La presencia de este tipo de profesionales en el Estado no es un fenómeno nuevo. Un estudio sobre la elite en puestos formales, realizado para el periodo 1948-1974, encontró que "los abogados constituyen la mayoría de los profesionales que han ocupado puestos en las ramas ejecutiva y legislativa del gobierno" (Arias Sánchez, 1974, 142).

De tal manera que la formación básica y la visión disciplinaria fue un elemento de cohesión de los negociadores, pues la disciplina también se convierte en la puerta de entrada principal a un campo temático muy general y a un campo amplio de problemas.

Los economistas en Costa Rica, como en otras partes del mundo, se abren camino dentro del Estado, en disputa con la élite de abogados que tuvo preeminencia en los principales puestos políticos desde fines del siglo XIX. A fines de los años cuarenta y en las dos décadas siguientes, Rodrigo Facio, abogado de formación, pero también un estudioso muy lúcido y original de la economía, es un ejemplo del avance de las posiciones de los economistas en la formulación de políticas estatales. Desde entonces, las profesiones de derecho y economía constituyeron medios de ascenso profesional dentro del Estado costarricense, situación que para poder mantenerse requirió del aumento de la especialización y la competitividad de esas profesiones en términos del mercado internacional.

Con respecto al periodo 1985-1995, en el cual se formularon las políticas de ajuste estructural impulsadas por los organismos financieros internacionales, Raventós (1997) llamó la atención sobre la unidad disciplinaria de los funcionarios que participaron en el proceso de negociación. 
Así pues, cuando se analiza la formación disciplinaria dominante en los equipos que negociaron el ajuste estructural en América Latina, se evidencia que estuvieron conformados mayoritariamente por economistas. Mientras que, en el caso del TLC con Estados Unidos, aunque la dirección estuvo en manos de un economista, la gran mayoría de negociadores eran abogados. Esto es válido tanto para los jefes de las mesas de negociación, como para el grupo ampliado que participó en el proceso.

\section{De la socialización anticipatoria a la construcción de comunidad}

Se puede decir que el carácter anticipatorio de la socialización de los negociadores tiene una dimensión nacional y una dimensión internacional y constituye un proceso. Por un lado, comienza a gestarse desde la elección disciplinaria, nacionalmente, a través de relaciones de modelaje o de mentor-aprendiz que se construyeron internamente, es decir, en Costa Rica. Por otro lado, pasa por los estudios de posgrado en universidades norteamericanas o inglesas, hasta culminar con la adopción del paradigma promercado de los negociadores y funcionarios internacionales.

Una de las formas en las que se expresan las relaciones de poder asimétricas, entre Estados Unidos y Costa Rica, consiste en lo que Dezalay y Garth (2002) denominan la dolarización del saber. De acuerdo con estos autores, algunas disciplinas toman del país poderoso los modelos profesionales que les den expectativas de acceso al Estado y al poder. La Tabla 2 muestra que, para los negociadores costarricenses, Estados Unidos es un sitio de referencia para el modelaje profesional, pues cinco de ellos hicieron posgrados en ese país, en tanto que dos optaron por Inglaterra.

No parece casual que cuatro negociadores estudiaron en la Universidad de Georgetown, dos de ellos hicieron estudios en la John F. Kennedy School of Management de la Universidad de Harvard y dos se formaron en la London School of Economics en Inglaterra. La formación en el extranjero no solo les permitió tener acceso a una nueva tecnología estatal, sino también reproducirla; con lo cual se forman otras generaciones de negociadores. Por ejemplo, Anabel González, quien funda una Cátedra de Comercio Exterior en la Facultad de Derecho de la Universidad de Costa Rica.

A partir de estos posgrados, fuera y dentro del país, y los requerimientos de la OMC, se consolida una nueva especialidad en materia de negociación y de aplicación de tratados comerciales, la cual genera la problemática y el expertise para atenderla.

Para complementar esta visión sobre instituciones, espacios y personas de referencia en la socialización de los negociadores, se presenta a continuación a las personas que algunos de ellos reconocieron como sus mentores. 
Tabla 3

MENTORES DE LOS NEGOCIADORES

\begin{tabular}{lll}
\hline Negociador & Mentores reconocidos & Comentarios \\
\hline Anabel González & Eduardo Lizano F. & "He aprendido no solo mucho sobre la \\
& materia de fondo, sino también de la \\
& Diego Baudrit (profesor de & rigurosidad intelectual, la acuciosidad \\
& Contratos) y Carlos José Gutiérrez & y la integridad". \\
& (profesor de Derecho & "Ambos me enseñaron sobre la \\
& Constitucional). & excelencia, la importancia del compro- \\
& Charles Verrill, de & miso, el análisis profundo y riguroso". \\
& Georgetown University & "Él consolidó en mí el interés por el \\
& & comercio internacional, el cual \\
& & mantengo hasta el día de hoy". \\
\hline Gabriela Llobet & Francisco Chacón & "Específicamente en este tema \\
& & Francisco Chacón y Anabel González". \\
& & Ella en Comercio Internacional \\
& & y él en Derecho Administrativo \\
& & (Comunicación personal, 10 de abril \\
& & de 2008). \\
\hline Fernando Ocampo & Anabel González y & "Fueron mis profesores, mis \\
& Francisco Chacón & directore de tesis, mis jefes y para \\
& & mí son medios de consulta muy \\
& & importante" (Comunicación personal, \\
& febrero del 2008). \\
\hline
\end{tabular}

Fuente: Comunicaciones personales y semanario El Financiero, 5 de marzo del 2007.

De acuerdo con lo expuesto en la Tabla 3, existe una conexión de admiración y tutelaje de Anabel González hacia su mentor Eduardo Lizano, asimismo, de Gabriela Llobet y Fernando Ocampo hacia Anabel González y Francisco Chacón. El influjo de Lizano sobre González durante la negociación del TLC con Estados Unidos fue analizado ya con más detenimiento en Molina (2009), la autora argumenta que: a) Eduardo Lizano Fait se convirtió en el hilo conductor del equipo económico negociador de los programas de ajuste estructural y también del equipo negociante del TLC con Estados Unidos, b) Lizano entrenó a Anabel González para la negociación del TLC con Estados Unidos y c) ese liderazgo de Lizano fue producto de la combinación de recursos académicos, relaciones sociales y puestos políticos (Molina, 2009, 178).

Ahora bien, los temas de los trabajos de graduación (licenciatura) de los negociadores versan sobre los siguientes asuntos: el sistema multilateral de comercio, el sistema estatal de comercio exterior costarricense, la disputa con la Unión Europea por el comercio del banano y las regulaciones ambientales dentro de los tratados comerciales. 
Tabla 4

TRABAJOS FINALES DE GRADUACIÓN DE CUATRO NEGOCIADORES DEL TLC

\begin{tabular}{|c|c|}
\hline Autor y título del trabajo & Problema y conclusión \\
\hline $\begin{array}{l}\text { Roberto Echandi Gurdián et al. (1991). } \\
\text { "La Ronda de Uruguay y el fortale- } \\
\text { cimiento del Sistema Multilateral de } \\
\text { Comercio del GATT". } \\
\text { Seminario de Graduación para optar } \\
\text { por el título de Licenciado en Derecho } \\
\text { de la Facultad de Derecho de la } \\
\text { Universidad de Costa Rica }\end{array}$ & $\begin{array}{l}\text { ¿Cuáles son los avances de los grupos de negociación en la } \\
\text { Ronda de Uruguay? } \\
\text { ¿Cuáles son los obstáculos para que el GATT pueda } \\
\text { tornarse en un "organismo de corte jurídico"? } \\
\text { En la Ronda de Uruguay "el sistema multilateral de } \\
\text { comercio del GATT no se ha visto fortalecido con los } \\
\text { resultados alcanzados en los diversos grupos de } \\
\text { negociación" (Echandi y otros, 1991, 437). }\end{array}$ \\
\hline
\end{tabular}

Fernando José Ocampo, Sánchez y

¿Cuáles son las diversas instituciones que intervienen en

Luis Alonso Madrigal Pacheco (1993).

el sector de comercio exterior?

“El Sistema Nacional de Comercio

"No existe un verdadero sistema que intervenga en las Exterior". Licenciatura en Derecho de la Universidad de Costa Rica. relaciones comerciales internacionales" sino "una serie de instituciones faltas de coherencia y que por sí solas tratan de llevar a cabo una política que les permita permanecer dentro del juego del libre mercado" (Ocampo et al., 1993, 214).

Federico Valerio de Ford (1993).

"Costa Rica, el banano y la

Comunidad Europea".

Trabajo Final de Graduación, en el Instituto del Servicio Exterior Manuel María Peralta.

Ministerio de Relaciones Exteriores y Culto, Gobierno de Costa Rica.
¿Cuáles son las reacciones y repercusiones en Costa Rica a raíz del sistema de cuotas impuesto por la comunidad europea a partir de julio de 1993?

“Junto con el resto de países productores de banano, el gobierno acordó realizar la lucha diplomática y utilizar los medios legales posibles para detener la aplicación de las medidas europeas.

Se realizó en el momento un panel con expertos que resultó beneficioso para los países productores de banano" (Valerio, 1993, 60).
Gabriela Llobet Iglesias (1995).

"Las regulaciones ambientales contenidas en el Tratado de Libre Comercio de América del Norte".

Licenciatura en Derecho
¿Cuáles son las principales disposiciones en materia ambiental contenidas en el Tratado de Libre Comercio de América del Norte (NAFTA, por sus siglas en inglés) y en el Acuerdo de Cooperación Ambiental?

Puede considerarse el NAFTA, como el tratado comercial que contiene la mayor cantidad de regulaciones ambientales que ningún otro en la historia, pero omite diversas medidas ambientales trascendentales (Llobet, 1995, 210).

Fuente: Tomado de las trabajos finales de graduación de cada negociador. 
La Tabla 4 permite ver que antes de que los negociadores participaran en el proceso del TLC con Estados Unidos, incluso antes de que entraran al COMEX, ya habían realizado estudios relacionados con el comercio. Su formación en esa materia facilita la entrada en el sector gubernamental de comercio exterior.

En Molina (2009) se resumen las ideas centrales de estos trabajos de graduación y se concluye que, a pesar de la diversidad temática, todos comparten no solo el interés por estudiar y promover la expansión de las relaciones comerciales, sino que también comparten varios supuestos no demostrados. Por ejemplo, el supuesto de que existe una relación positiva universalmente válida entre apertura comercial y desarrollo, además, el supuesto de que, a través de tratados comerciales y la técnica de negociación, los países pequeños pueden establecer relaciones simétricas con países desarrollados. Esa creencia general subyace como solución frente a problemas que son diversos y que tienen distintos orígenes o causalidades.

Lo anterior permite plantearse una pregunta: ¿se construyeron los negociadores como comunidad profesional o como grupo ideológico?, ¿pueden deslindarse los límites entre afirmaciones que emanan de una ideología y el saber que emana de un conocimiento profesional o científico?

Al respecto, Molina propuso el concepto de comunidad epistémica como categoría para describir al equipo negociador del TLC, esto de acuerdo con Adler y Haas (1992), quienes definen a esta comunidad como una red de profesionales que, al tener un reconocido expertise y competencia en un dominio particular, reclaman una autoridad de conocimiento relevante sobre las políticas. La comunidad puede involucrar distintas disciplinas, cuyas relaciones se caracterizan por compartir un conjunto de normas, principios y creencias causales; estos contribuyen a elucidar relaciones entre acciones políticas y resultados, dentro de un conjunto central de problemas de su dominio.

\section{Siguiendo trayectorias de ascenso profesional}

El concepto de socialización anticipatoria aporta algo más de lo hasta aquí señalado. Primero, porque se refiere al hecho de que los individuos que están subordinados o que aún no están integrados dentro de un espacio o grupo determinado muestran la tendencia a compartir los sentimientos y a conformarse con los valores centrales de los más prestigiosos y más respetados del grupo (Merton, 1949, 305-470).

Segundo, si la tendencia de los individuos, en el ámbito social, fuese identificarse no con su grupo de pertenencia (o grupo de origen), sino con el más prestigioso, la capacidad o la incapacidad de la estructura social para ofrecer posibilidades de movilidad social resultaría determinante. A su vez, ello tiene repercusiones para entender tanto los niveles de frustración colectiva como las combinaciones de valores, por ejemplo, la solidaridad y la competencia entre los individuos. 
En el caso de los negociadores del TLC, la socialización anticipatoria operó no solo al asumir valores y creencias de personajes prestigiosos, sino también al facilitar mecanismos de movilidad profesional. Se argumenta que ellos han seguido estrategias de socialización profesional particulares, las cuales los unen a las ansias de ascenso profesional, y que para ello optaron por la preparación profesional en el exterior, en carreras que tradicionalmente han servido para el ascenso y la incidencia política. Ambas cosas facilitadas por las relaciones familiares y sociales de su posición social.

Estos individuos tampoco están fuera de las tendencias socioeconómicas estructurales. Como Pérez Sáinz, (2004) planteó, surgió más bien un proceso de elitización de los profesionales, tanto en el sector público como privado, durante la década de 1990. Es decir, los profesionales aumentaron su participación en empleos de los más altos estratos sociocupacionales, lo cual produjo una movilización de los estratos medios a los altos, paralelamente, con una reducción de los estratos sociocupacionales menos calificados. De tal forma que, si bien hubo una reducción en términos absolutos, de 16368 puestos del grupo no profesionalizado del Estado (producto de la reforma), se incrementaron los puestos profesionalizados en 10 122. Lo anterior hace pensar en una modernización del sector público (Pérez, 2004, 58-62).

El hallazgo empírico aportado por Pérez Sáinz, para efectos de este trabajo, tiene relevancia en varios sentidos. En primer lugar, porque COMEX constituye el ejemplo por excelencia de la tendencia a la profesionalización de los servicios, en materia de comercio exterior, y a la promoción de inversión extranjera. En segundo lugar, porque el ascenso en la escalera social del grupo sociocupacional de profesionales, tanto del sector público como privado, sitúa el contexto estructural donde se ubican los negociadores del TLC como nuevos tipos de funcionario público. Las trayectorias de estos últimos constituyen ejemplos de carne y hueso de la tendencia encontrada por el autor, con respecto al paso de un grupo del nivel medio alto al nivel alto de la estructura sociocupacional.

Finalmente, en tercer lugar, las conclusiones de dicho autor sugieren una tendencia estructural, la cual explicaría, en parte, que algunos de los líderes centrales de la negociación comercial con Estados Unidos hayan emigrado hacia el sector privado en forma aparentemente duradera. ${ }^{5}$ Dicho lo anterior, hay que señalar también que, pese a los elementos compartidos por los negociadores, ellos siguieron trayectorias laborales con énfasis diferentes. ${ }^{6}$

Si se toman como dos aspectos claves el ámbito nacional o internacional de la ubicación laboral y el vínculo con el sector público o privado de la contratación, se pueden visualizar tres tipos de apuestas por parte de los principales miembros del equipo negociador. En primer lugar, una apuesta profesional hacia el campo internacional, lo cual se puede denominar como una identidad transnacional. En este grupo, el elemento clave está dado por la ejecución de la tarea fuera del país de origen y puede realizarse desde el sector público o privado. 
En segundo lugar, una línea de acción optó por trabajar en y para el sector privado. Fundamentalmente, se ubica en el territorio nacional, pero establece vínculos laborales tanto con el sector empresarial nacional como extranjero. En tercer lugar, una apuesta que puede visualizarse en los negociadores vinculados directamente con el sector público estatal.

El primer grupo se denomina "volcado a lo transnacional" o cosmopolita. El segundo se identifica como proempresarial; y el tercero, como burócrata o técnico promercado. Dentro del primer grupo se ubican Anabel González y Roberto Echandi. Al segundo grupo pertenecen Alberto Trejos, Gabriela Llobet y Fernando Valerio. En el tercero pueden encontrarse Fernando Ocampo, Amparo Pacheco, Mariel Picado e Irene Arguedas.

Es notable que en los tres tipos de trayectorias se produjo una combinación entre el uso de capital profesional o capital social (a partir de la disponibilidad), de las fortalezas personales y de las necesidades prácticas.

Desde el punto de vista de la propia historia laboral de cada negociador, es evidente que el tema de la negociación de los tratados comerciales se constituyó en un medio para el ascenso social. En la Tabla 5, por ejemplo, puede notarse que los negociadores escalaron posiciones en forma paralela al desarrollo de un campo burocrático que ellos mismos ayudaron a construir. 
Tabla 5

CARRERA DE ASCENSO SEGÚN PUESTO Y TIPO DE NEGOCIADOR

\begin{tabular}{|c|c|c|c|}
\hline & Antes del 2003 & Durante 2003-2004 & Después del 2005 \\
\hline Perfil transnacional & Puesto & Puesto & Puesto \\
\hline Anabel González & $\begin{array}{l}\text { Diciembre 2000- } \\
\text { mayo 2001: Directora } \\
\text { General de Coalición } \\
\text { Costarricense de } \\
\text { Iniciativas para el } \\
\text { Desarrollo (CINDE). }\end{array}$ & $\begin{array}{l}\text { Diciembre 2002-septiem- } \\
\text { bre 2004: Embajadora } \\
\text { Especial para asuntos } \\
\text { Comerciales con Estados } \\
\text { Unidos. }\end{array}$ & $\begin{array}{l}\text { Directora del } \\
\text { Departamento de } \\
\text { Agricultura de la } \\
\text { Organización Mundial } \\
\text { del Comercio. }\end{array}$ \\
\hline Roberto Echandi & $\begin{array}{l}\text { 1998: Director General } \\
\text { de Comercio Exterior } \\
\text { en COMEX. } \\
\text { 2001: Negociador en } \\
\text { varios tratados. }\end{array}$ & $\begin{array}{l}\text { 2002-2005: Embajador } \\
\text { Adjunto para asun- } \\
\text { tos comerciales con } \\
\text { Estados Unidos desde el } \\
\text { Ministerio de Relaciones } \\
\text { Exteriores. } \\
\end{array}$ & $\begin{array}{l}\text { Embajador y jefe nego- } \\
\text { ciador del Acuerdo de } \\
\text { Asociación con la Unión } \\
\text { Europea. }\end{array}$ \\
\hline \multicolumn{4}{|c|}{ Perfil sector privado, área de comercio internacional } \\
\hline Gabriela Llobet & $\begin{array}{l}\text { Directora de } \\
\text { Aplicaciones } \\
\text { Comerciales en } \\
\text { COMEX. }\end{array}$ & $\begin{array}{l}\text { 2002-2004: } \\
\text { Viceministra de } \\
\text { Comercio exterior. }\end{array}$ & $\begin{array}{l}\text { Septiembre 2004-junio } \\
\text { 2007: Gerente de Asuntos } \\
\text { Corporativos en Intel } \\
\text { Julio 2007: Dirección } \\
\text { General de CINDE }\end{array}$ \\
\hline Federico Valerio & & $\begin{array}{l}\text { 2002-2004: } \\
\text { Subdirector de } \\
\text { Negociaciones } \\
\text { Comerciales } \\
\text { Internacionales y } \\
\text { Subdirector de } \\
\text { Aplicación de Acuerdos } \\
\text { Comerciales en COMEX. }\end{array}$ & \\
\hline \multicolumn{4}{|l|}{ Perfil sector estatal } \\
\hline Fernando Ocampo & $\begin{array}{l}\text { Asistente de despacho } \\
\text { del viceministro. } \\
\text { Asesor } \\
\text { negociador. }\end{array}$ & $\begin{array}{l}\text { 2001-2005: } \\
\text { Director de aplicaciones. } \\
\text { Director de negociaciones. } \\
\text { Director General de } \\
\text { Comercio Exterior de } \\
\text { Costa Rica. }\end{array}$ & $\begin{array}{l}\text { Jefe adjunto para negocia- } \\
\text { ciones comerciales. }\end{array}$ \\
\hline Amparo Pacheco & $\begin{array}{l}\text { Jefa de Despacho de } \\
\text { Viceministro. }\end{array}$ & $\begin{array}{l}\text { Encargada de las relacio- } \\
\text { nes con la sociedad civil } \\
\text { en COMEX. }\end{array}$ & Viceministra de COMEX. \\
\hline
\end{tabular}

Fuente: Hojas de vida y entrevistas personales. 
Este ascenso puede considerarse vertiginoso con respecto a su propia trayectoria, lo cual puede vislumbrarse en las diferencias salariales durante su proceso de ascenso.

En materia de saber profesional, esta generación de abogados se abrió campo en una nueva área: negociación de tratados comerciales. Las trayectorias denotan movimientos de ida y vuelta del sector público al privado; y del ámbito nacional al internacional.

A partir de sus trayectorias se evidencia que la disciplina y los estudios en el exterior aportan conocimiento y relaciones; además, que lo fundamental del saber hacer que utilizan en su trabajo proviene de la misma escuela del Estado, la cual se convierte, entonces, en una "universidad del saber hacer".

Las relaciones sociales y contactos políticos de los dos líderes del equipo negociador jugaron un papel notorio en las oportunidades del equipo mismo para acceder a otras relaciones y puestos, dentro y fuera del país.

Por ejemplo, el ministro de Comercio, Alberto Trejos Zúñiga, es hijo del médico y político liberal Fernando Trejos Escalante, quien fue: diputado en el periodo 19661970, candidato presidencial perdedor para el periodo 1974-1978 y por segunda vez diputado en el periodo 1982-1986. Mientras que su padre fue miembro de la Sociedad Mont Pelerin desde 1970, Trejos Zúñiga participa de la Academia Centroamericana, ambas agrupaciones de pensamiento liberal. En esta última, Trejos Zúñiga, coincide con Eduardo Lizano, Anabel González y Andrés Rodríguez Clarke, este último hijo del expresidente de la República Miguel Ángel Rodríguez (1998-2002). 
Tabla 6

DIFERENCIAS SALARIALES ENTRE NEGOCIADORES

\begin{tabular}{|c|c|c|}
\hline Negociador & Salario en marzo 2004 & $\begin{array}{l}\text { Salario a partir de } \\
\text { abril } 2004\end{array}$ \\
\hline Anabel González & $\begin{array}{l}\text { USD } 8700 \\
\text { CRC } 4036800\end{array}$ & $\begin{array}{l}\text { Contrato por } \\
\text { servicios } \\
\text { profesionales }\end{array}$ \\
\hline Roberto Echandi & $\begin{array}{l}\text { USD } 8200 \\
\text { CRC } 3804800\end{array}$ & $\begin{array}{l}\text { Contrato por } \\
\text { servicios } \\
\text { profesionales }\end{array}$ \\
\hline $\begin{array}{l}\text { Fernando Ocampo } \\
\text { De Director de Negociaciones a Director General } \\
\text { de Comercio Exterior }\end{array}$ & CRC 1560000 & $\begin{array}{l}\text { CRC } 2250000 \\
\text { (CRC } 690000)\end{array}$ \\
\hline $\begin{array}{l}\text { Amparo Pacheco } \\
\text { (Directora de Aplicaciones y Jefa de Despacho a } \\
\text { Encargada de Sociedad Civil) }\end{array}$ & CRC 1260000 & $\begin{array}{l}\text { CRC } 1800000 \\
(\text { CRC } 540000)\end{array}$ \\
\hline $\begin{array}{l}\text { Federico Valerio } \\
\text { De Subdirector de Aplicaciones a Subdirector de } \\
\text { Negociaciones }\end{array}$ & CRC 1116000 & $\begin{array}{l}\text { CRC } 1550000 \\
(\text { CRC } 434000)\end{array}$ \\
\hline $\begin{array}{l}\text { Álvaro Monge } \\
\text { De Negociador Comercial } 3 \text { a Negociador } \\
\text { Comercial } 5\end{array}$ & CRC 976000 & $\begin{array}{l}\text { CRC } 1350000 \\
(\text { CRC } 374000)\end{array}$ \\
\hline $\begin{array}{l}\text { Juan Luis Zúñiga } \\
\text { De Negociador Comercial a Subdirector de } \\
\text { Aplicaciones Comerciales }\end{array}$ & CRC 948000 & $\begin{array}{l}\text { CRC } 1550000 \\
(\text { CRC } 601000)\end{array}$ \\
\hline $\begin{array}{l}\text { Irene Arguedas } \\
\text { De Directora de Negociaciones a Directora de } \\
\text { Negociaciones y Asesorías }\end{array}$ & CRC 1260000 & CRC 1800000 \\
\hline
\end{tabular}

Fuente: Diario Extra 1 de junio de 2005. Tipo de cambio del 2003: CRC 464 por USD 1.

El acceso a oportunidades varía según los recursos disponibles para cada negociador y las diferentes trayectorias que siguieron. Aun así, todos combinaron los recursos profesionales y las relaciones familiares, sociales y políticas en su trayectoria laboral.

\section{Comunidades epistémicas, producción de políticas e institucionalización}

En este apartado se argumenta que los agentes individuales estudiados forman parte de entramados de intereses, ideas, valores y relaciones sociales, a través de los cuales se construyen las políticas y los procesos de institucionalización de ciertas prácticas. 
Los mecanismos a través de los cuales se produjeron cambios sustanciales en las políticas y en las instituciones de desarrollo de Costa Rica fueron los siguientes: la adopción de un paradigma de apertura comercial inspirado en ideas económicas y legitimado por el derecho; una forma de gestión e institucionalización de la política; y el uso de la racionalidad técnica como mecanismo de legitimación.

En relación con el Estado y la política, el trabajo de Bourdieu tiene la ventaja de que permite visualizar a ambos, también, como campos y como productos de las disputas entre diversas fuerzas sociales. Lo específico del campo estatal, para ese autor, no radica solo en detentar el monopolio de la fuerza física, como diría Weber, sino en ostentar el poder de definir las normas que rigen una sociedad.

Por lo tanto, el Estado no es una realidad unificada y definida, sino un conjunto de campos burocráticos o administrativos, donde confluyen agentes gubernamentales y no gubernamentales, muchas veces organizados en comisiones:

A luchar por esta forma particular de poder que es el poder de regir una esfera particular de prácticas [por ejemplo comercio exterior] mediante leyes, reglamentos, medidas administrativas (subsidios, autorizaciones, etc.), en fin todo aquello que corresponda a una politica" (Bourdieu, 1992, 75).

Aunque en el Estado el capital propiamente burocrático consiste en la gestión de los reglamentos, este capital es objeto de interés de otros agentes ubicados en distintas instituciones estatales o en otros campos. Por lo anterior, el Estado es una instancia privilegiada dentro del campo de poder, donde quienes tienen acceso a este obtienen un capital específico, el cual consiste en alcanzar poder sobre las diferentes especies de capital, sus tasas de intercambio y su reproducción. Esto produce una relación estrecha entre el acceso al Estado y el vínculo con el campo de poder y con la clase dirigente. De hecho, el poder sobre el Estado es parte de la lucha que se libra dentro del campo de poder (Bourdieu, 1992, 76). ${ }^{7}$

Cuando se afirma que los negociadores constituyeron una nueva elite estatal, se entiende que formaron la parte estatal de las negociaciones comerciales, afines a la nueva elite transnacional de la cual hablan diversos analistas, tales como Robinson (2001), Schneider (2014), entre otros.

\section{Compartiendo un paradigma de política: De la postura individual a la posición nacional}

Si en el apartado anterior se sostuvo que la socialización anticipatoria es un mecanismo que permite entender cómo determinados individuos adoptan valores y creencias, al imitar modelos o personajes de referencia; en este apartado se sostiene que de esos procesos pueden emerger políticas públicas, cuando los agentes sociales involucrados que las gestionan pasan de socializados a socializadores. 
Los paradigmas pueden ser visualizados como ejes aglutinadores de políticas y aportar, también, elementos para entender los factores que explican el cambio en los procesos de formulación de las políticas públicas.

Al hacer una analogía con el proceso de producción de conocimientos científicos, Peter Hall (1993) señala:

Los gestores de la política pública comúnmente trabajan dentro de esquemas de ideas y parámetros que especifican no solo las metas de la politica y los tipos de instrumentos que pueden ser usados para lograrlas, sino también la naturaleza de los problemas que ellos intentan tratar (Hall, 1993, 279).

Tal como se afirmó en el apartado anterior, los negociadores compartieron algo más que códigos profesionales homogéneos que brinda la disciplina. También tenían en común ideas claves que les dieron cohesión ideológica y que consolidaron el cambio de paradigma en las políticas comerciales.

Como señaló Fernando Ocampo, uno de los negociadores del TLC, a fines de la administración Rodríguez Echeverría (1998-2002), cuando se le preguntó sobre el futuro del COMEX: "Si viene alguien dispuesto a mantener la política de apertura comercial que se ha venido desarrollando desde hace 10 años, no creo entonces que la situación cambie mucho" (Bermúdez, 2001). Ese núcleo ideológico compartido promercado y proapertura comercial se vio fortalecido por el matrimonio entre leyes y economía.

El trabajo de graduación de uno de los negociadores, Echandi, en coautoría con otras personas, ejemplifica cómo se construye ese acoplamiento, al afirmar que existe, por un lado, una subordinación de las normas a las relaciones de poder económico y, por otro lado, un ideal de que el derecho juega un papel central en el cambio social actual que ellos querían impulsar.

En relación con lo primero, los autores del trabajo señalan que: "Si los procesos económicos son cíclicos, no es menos cierto que el rol del Derecho Internacional Económico varía en forma paralela a ese ciclo" (Echandi, 1991, 948-949). Ese rol se maximiza como un instrumento de desarrollo y de crecimiento económico cuando coinciden las necesidades y posibilidades de los países poderosos, de tal manera que la competencia los lleve a establecer convenios internacionales de comercio, con lo cual arrastran a los países de menor desarrollo. Agregan, además: “Para que el Derecho funcione como instrumento de cambio social se necesita una autoridad fuerte capaz de imponer el cambio que prescriben las normas" (948-949). A su juicio, este cambio estaba ocurriendo de manera incipiente cuando se negoció la Ronda de Uruguay, entre 1986 y 1993.

El hecho de que en el equipo principal de negociadores se incluyeran dos economistas (Trejos y Pacheco) ${ }^{8}$ y que el resto del equipo tuviera formación en derecho muestra que la apertura comercial parece haberse convertido en un puente entre 
formaciones tan distintas. Lo anterior en la medida en que una disciplina aporta una visión sobre el orden económico y la otra incorpora formas y procedimientos para legalizarlo.

Cuando se analiza el documento que emitió COMEX sobre “la posición nacional" en torno al TLC, se visualiza claramente la forma en la que pueden amalgamarse ideas económicas y fundamentos jurídicos. El principal argumento de la "posición nacional", para negociar un TLC con los Estados Unidos, fue de carácter jurídico, pues se afirmó que las disposiciones vigentes en la relación bilateral, hasta el momento, habían sido determinadas de forma unilateral por el gobierno de Estados Unidos. Dado que el país no tenía control sobre los términos, las modificaciones o la duración de las disposiciones de la Iniciativa para la Cuenca del Caribe (CBI, por sus siglas en inglés). Por lo anterior, se consideró fundamental:

Convertir ésta en una relación bilateral permanente, y que se establecieran reglas y disciplinas bilaterales, así como se planteó que debía contener un mecanismo de solución de diferencias transparente y ágil. Solo así, se argumentó que podrán los países de la región consolidar y dar certeza jurídica a los términos comerciales que le vinculan con su principal mercado (COMEX, 2003).

Así las cosas, se puede afirmar que los negociadores compartieron creencias en torno a los problemas centrales del desarrollo costarricense y sus posibles soluciones. Establecieron relaciones de causalidad entre liberalización comercial y desarrollo y consideraron la apertura de mercados como un mecanismo de solución ante diversos problemas ligados al desarrollo económico y social. Se trata, entonces, de uno de los supuestos claves que compartieron tanto los negociadores de formación básica en economía como los formados en derecho.

La visión de los negociadores forma parte de un tejido estatal y social mayor, pues desde otras instituciones, como el Banco Central, algunos funcionarios mentores explicitaron muy claramente el vínculo que debía existir entre política comercial y derecho. En ese sentido, se señaló que una de las áreas de acción inmediata de la política comercial estaba relacionada con el del estado de legalidad. Este se considera indispensable para crear un entorno propicio para el desarrollo de las empresas, puesto que se asegura el respeto al derecho de propiedad, la validez de los contratos, la justicia pronta y cumplida, así como la seguridad de personas y bienes. De tal manera que el derecho crea las bases para el funcionamiento del mercado, al adoptar premisas de ciertas visiones de la economía y la teoría comercial (Lizano, 2001, 25).

El hecho de que prácticamente todos los negociadores hayan estudiado leyes aportó un código disciplinario que facilitó la comunicación entre ellos. No obstante lo anterior, los contenidos sustantivos del TLC provinieron fundamentalmente de 
teorías de crecimiento y de desarrollo inspiradas en teorías económicas neoclásicas, mezcladas con elementos de otras áreas como la administración de negocios y las relaciones internacionales.

\section{La gestión de la política}

La forma en que se organizó el equipo negociador del TLC es particularmente novedosa, porque sus integrantes no se convirtieron en actores tanto por su lugar con respecto a las estructuras del poder, como por su funcionalidad en relación con estas. Aunque la diferencia parece sutil, se trata de un actor colectivo de nivel intermedio (entre el sistema internacional y el Estado nación) que, jugando con los márgenes entre la voluntad individual y las estructuras de poder, a partir de su saber experto, puede contribuir de cierta forma a generar nuevos valores, nuevas prácticas y nuevas políticas públicas cardinales y duraderas.

A diferencia de las relaciones establecidas por el equipo económico que negoció el ajuste estructural, carente de un asidero institucional claramente establecido, el equipo de negociadores del TLC con Estados Unidos sí se implantó dentro de una institución con las potestades para negociar tratados comerciales, además, se formó, en su mayoría, con funcionarios públicos, cuyo reclutamiento se justificó en términos de sus credenciales profesionales y su saber experto en la materia.

El grupo puede dividirse en cuatro tipos de funcionarios:

a) El ministro de Comercio que representa al Poder Ejecutivo.

b) La Embajadora Especial de Negociaciones que vendría a ser una técnica generalista o una experta en su campo.

c) Un grupo de cinco a ocho profesionales que ejercieron el rol de jefes de las mesas de negociación temáticas. ${ }^{9}$

d) Un amplio grupo de funcionarios de distintas instituciones públicas que participaron como asesores en aspectos y momentos puntuales de la negociación. Se trata de alrededor de treinta personas.

La estructura de la negociación se hizo de acuerdo con los temas establecidos por la OMC y se crearon cinco mesas y dos grupos de trabajo. 
JEFES, MESAS DE NEGOCIACIÓN Y GRUPOS DE TRABAJO

\begin{tabular}{ll}
\hline Mesa de negociación o grupo & Jefe \\
\hline Acceso a mercados & Fernando Ocampo \\
\hline $\begin{array}{l}\text { Servicios e inversión } \\
\text { Grupo de trabajo sobre cooperación internacional }\end{array}$ & Roberto Echandi \\
\hline Ambiente laboral & Gabriela Llobet \\
\hline Propiedad intelectual y compras del sector público & Federico Valerio \\
\hline Solución de controversias y disposiciones institucionales & Mariel Picado \\
\hline Textiles & $\begin{array}{l}\text { Irene Arguedas } \\
\text { (negociadora adjunta) }\end{array}$ \\
\hline Grupo de trabajo de medidas sanitarias y fitosanitarias & Álvaro Monge \\
\hline
\end{tabular}

Fuente: Elaboración propia a partir de El Financiero, 12 de noviembre de 2003.

Se puede decir que el formato de gestión aplicada llevó a una alta inversión de recursos destinados a presentar los contenidos como innovaciones y a promover los acuerdos como parte de una tendencia internacional insoslayable. Asimismo, el lugar desde el cual los negociadores se convirtieron en actor colectivo les posibilitó generar un puente entre lo local y lo global, entre el Estado nación y los otros Estados; esto permite cooperar en la construcción de instituciones internacionales. Lo anterior se logra, según Robert Putman, citado por Adler y Haas $(1992,373)$, a través de un "juego de dos niveles", tanto nacional como internacionalmente. En ese sentido, la posibilidad de que los negociadores del TLC se convirtieran en actores sociales influyentes surge ante la oportunidad de rentabilizar su saber experto y su capacidad de negociar en el mercado de las ideas y las políticas.

Para ilustrar algunos de los aspectos que hacen del equipo negociador parte de una comunidad epistémica inédita, en la Tabla 8 se comparan las fases de la gestión de dicho acuerdo y el caso del equipo económico que negoció el ajuste estructural en Costa Rica. 
Tabla 8

EQUIPOS, IDEAS Y FASES DE POLÍTICA: EL CASO DEL AJUSTE ESTRUCTURAL Y EL DEL TLC

\begin{tabular}{|c|c|c|}
\hline Fase/política & Ajuste estructural & TLC \\
\hline $\begin{array}{l}\text { Innovación } \\
\text { Una organización nacional o } \\
\text { internacional toma una innovación } \\
\text { intelectual, inyecta valores y } \\
\text { expectativas a nivel nacional. }\end{array}$ & $\begin{array}{l}\text { Reuniones ministeriales } \\
\text { Consenso de Washington } \\
\text { Apertura y liberalización } \\
\text { comercial }\end{array}$ & $\begin{array}{l}\text { OMC } \\
\text { Anti proteccionismo } \\
\text { Desgravación arancelaria }\end{array}$ \\
\hline $\begin{array}{l}\text { Selección } \\
\text { Mediante un proceso político la } \\
\text { innovación sirve de base para } \\
\text { definir intereses nacionales. }\end{array}$ & $\begin{array}{l}\text { Equipo económico de los } \\
\text { gobiernos de Luis Alberto } \\
\text { Monge Álvarez (1982- } \\
\text { 1986), a partir de 1985, y de } \\
\text { Óscar Arias Sánchez (1986- } \\
\text { 1990), hasta 1989, ambos } \\
\text { del Partido Liberación } \\
\text { Nacional, presentan pro- } \\
\text { puestas de organismos } \\
\text { internacionales en la } \\
\text { Asamblea Legislativa. }\end{array}$ & $\begin{array}{l}\text { Proceso político para conse- } \\
\text { guir su aprobación, a partir } \\
\text { del gobierno de Abel Pacheco } \\
\text { (2002-2006), del Partido Unidad } \\
\text { Social Cristiana, y del gobierno } \\
\text { de Óscar Arias Sánchez, del } \\
\text { Partido Liberación Nacional, a } \\
\text { través de talleres técnicos, nueve } \\
\text { rondas de negociación y trámite } \\
\text { del proyecto en la Asamblea } \\
\text { Legislativa, así como también el } \\
\text { referendo del año } 2007 \text {. }\end{array}$ \\
\hline \multirow[t]{3}{*}{$\begin{array}{l}\text { Difusión } \\
\text { Nacional, transnacional. }\end{array}$} & $\begin{array}{l}\text { Secretismo: Ausencia de } \\
\text { documentos públicos sobre } \\
\text { negociaciones. } \\
\text { Prevalece lenguaje } \\
\text { técnico. }\end{array}$ & $\begin{array}{l}\text { En el ámbito nacional, se } \\
\text { consultó/informó a } 467 \\
\text { organizaciones y } 900 \text { empresas. } \\
\text { Durante la negociación, a } \\
\text { través del cuarto adjunto, } \\
\text { participaron } 153 \text { agrupaciones } \\
\text { y hubo } 60 \text { reuniones. } \\
\text { Lenguaje técnico. }\end{array}$ \\
\hline & & $\begin{array}{l}\text { A nivel regional, equipo costa- } \\
\text { rricense con liderazgo regional. }\end{array}$ \\
\hline & & $\begin{array}{l}\text { A nivel internacional, } \\
\text { negociadores exportan la } \\
\text { experiencia. }\end{array}$ \\
\hline $\begin{array}{l}\text { Persistencia/Institucionalización } \\
\text { Instituciones y prácticas nuevas } \\
\text { sirven de base a un nuevo orden } \\
\text { internacional. }\end{array}$ & $\begin{array}{l}\text { Reformas de política } \\
\text { económica consolidadas y } \\
\text { reformas estatales mixtas. }\end{array}$ & $\begin{array}{l}\text { Organización Mundial del } \\
\text { Comercio (OMC). } \\
\text { Costa Rica: } 9 \text { tratados } \\
\text { comerciales. }\end{array}$ \\
\hline & & TLC con alcance regional. \\
\hline
\end{tabular}

Fuente: Elaboración propia a partir de Adler y Haas (1992); Raventós (1997) y Doryan (1990). 
A partir de la Tabla 8, se podría decir que, tanto en la negociación de los préstamos del ajuste estructural como en el TLC con Estados Unidos, los organismos e instituciones internacionales jugaron un papel clave durante la primera fase.

Durante la segunda fase, en el ámbito legislativo del proceso político interno de las negociaciones del ajuste estructural, se destacó el lugar que tuvo el uso lenguaje técnico como recurso de legitimación del equipo económico del Gobierno frente a los políticos y empresarios y el papel que jugaron como intermediarios entre estos y los organismos financieros internacionales. Veinte años después, en la negociación del TLC, este recurso vuelve a jugar un papel clave como mecanismo de legitimación.

Precisamente, en el caso del TLC, se puede decir que la comunidad epistémica tuvo éxito porque contó con la existencia de una coalición política amplia que apoyó el tratado. Esta situación no constituye un evento inédito en Costa Rica, antes bien, en otras épocas históricas ${ }^{10}$ surgió la confluencia de ideas profesionales y de agendas de partidos políticos en ascenso, las cuales hicieron de la comunidad epistémica un grupo exitoso.

Se generó, además, un proceso de difusión y aprendizaje colectivo sobre el TLC, a lo largo del periodo 2004-2007, inicialmente se promovió el envío del proyecto a la Asamblea Legislativa, después, su cabildeo dentro de esta y, por último, la campaña presencial y mediática para participar en el referéndum a favor del movimiento del Sí al TLC. El proceso tuvo diversos niveles y distintos destinatarios. Primero se realizaron, con los funcionarios estatales de los países centroamericanos, cinco talleres técnicos, entre agosto del 2001 y diciembre del 2002. Luego, se involucraron otras instituciones del Estado, empresas privadas y organizaciones sociales, a través de distintos foros y del cuarto adjunto, durante las nueve rondas de negociación del año 2003. Al respecto, aunque Martínez (2004) evidencia que se trató más de un proceso de información que de consulta sobre los contenidos de fondo de la política no cabe duda de que sí hubo un proceso de difusión inédito en el país.

\section{La racionalidad técnica como mecanismo de legitimación}

En este apartado se argumenta que los negociadores se autopercibieron y fueron percibidos como técnicos, en contraste con quienes son considerados políticos. Esto se hizo desde una visión que percibe los asuntos técnicos como si estuviesen exentos de implicaciones políticas y del juego del poder.

Se plantea también que la racionalidad técnica, presumida por el equipo negociador en el proceso de construcción y negociación del TLC, funcionó más como un mecanismo de legitimación estatal que como un instrumento de producción de conocimientos o de construcción de acuerdos políticos con validación científico-profesional.

Finalmente, se sostiene que, para que la validación esté amparada en conocimiento riguroso, es necesario superar el mito de la neutralidad valorativa ${ }^{11}$ y dar paso a la construcción de acuerdos y mecanismos de objetivación, en el interior de las comunidades de saberes en disputa. 
En relación con la percepción de los negociadores del TLC, cabe mencionar el reconocimiento público que recibieron de parte de ciertos sectores durante la negociación, pues hubo quienes destacaron la "alta calidad, coherencia con los intereses del país y una unidad inquebrantable entre ellos" (La Nación, 21 de diciembre de 2003). Entre quienes así lo hicieron, puede mencionarse al agregado comercial de ese momento en la Embajada de Estados Unidos, Todd Chapmann, quien afirmó sobre los negociadores que: "se trata de un equipo de clase mundial". Además, se habló de su gestión como un hecho heroico y aparecieron grandes titulares como: "Apoyo total al equipo costarricense: decisión logró unidad nacional” (La Nación, 21 de diciembre de 2003). Al finalizar la novena ronda de negociación, para unos sectores los negociadores habían traicionado el interés nacional; mientras que para otros se había hecho un gran papel, al retirarse del cierre de la negociación y haber solicitado más tiempo para seguir. Esta decisión diferenció a Costa Rica de los demás países del istmo centroamericano.

En cualquier caso, fue la prensa nacional la que le reconoció más méritos a este equipo y los denominó “los personajes del 2003”. Tres años más tarde, recién llegado al poder para su segundo mandato (2006-2010), Óscar Arias Sánchez afirmó que le pediría a los negociadores del TLC con Estados Unidos participar en las negociaciones de otro tratado, ahora con la Unión Europea, pues a su juicio ellos "son costarricenses, tienen el conocimiento, tienen la experiencia" y agregó que se necesitarían negociadores fuertes para defender los intereses del país en un proceso que él ha considerado "muy difícil", por el proteccionismo europeo a sus productos (La Nación, 11 de mayo de 2006).

El expertise atribuido a los negociadores coincide con la autopercepción que ellos tienen de su papel. En la Tabla 9 se pueden observar algunas afirmaciones de los negociadores que ejemplifican lo dicho anteriormente.

Tabla 9

AUTOPERCEPCIONES DE LOS NEGOCIADORES DEL TLC

Alberto Trejos: "El objetivo de nuestra generación debe ser que nuestro país se convierta en el primer país desarrollado de América Latina" (Comunicación personal, 2007).

Anabel González: "Cuando hay razón y las cosas se preparan adecuadamente, se puede obtener lo que uno busca" (Comunicación personal, 2007).

Roberto Echandi: "Aquí lo que importa es evitar los ataques personales y volver a las ideas".

Fernando Ocampo: "Aquí nadie trabaja por un ministro, la gente es muy técnica y comprometida con los intereses del país" (Bermúdez, 2001). ${ }^{12}$

"Yo soy un técnico enamorado de lo que hago... yo siempre estoy el plano técnico, mi trabajo es dar insumos para que alguien más tome decisiones políticas" (Comunicación personal, 4 de febrero de 2008).

Gabriela Llobet: "Realmente mi fortaleza era la parte más técnica" (Comunicación personal, 10 de abril de 2008).

Amparo Pacheco: “yo llegué al puesto de viceministro... fundamentalmente por la vía técnica y no política" (Comunicación personal, 17 de enero de 2008).

Fuente: Comunicaciones personales y entrevistas. ${ }^{13}$ 
En las afirmaciones de esos cuatro negociadores se nota que mantenerse en el plano técnico es parte del profesionalismo al cual aspiran y que ellos comparten la creencia en la separación del ámbito técnico y político. Además, se autoperciben como "gente de ideas".

¿Por qué se afirma que la racionalidad técnica, presumida y atribuida al equipo negociador en el proceso de construcción y formación de esta política, funcionó como un mecanismo de legitimación estatal? Básicamente por tres razones: en primer lugar, la dicotomía que ellos mismos establecieron entre saberes técnicos y políticos es falsa; en segundo lugar, ningún espacio de producción de conocimiento está exento de las disputas del poder; y, en tercer lugar, la validez se construye no a través del distanciamiento de los valores culturales, sino a través de mecanismos tales como la persuasión lógica argumentativa, la rigurosidad metodológica y la evidencia empírica (Lahire, 2006).

La separación entre saberes técnicos y políticos y, más aún, entre ámbitos técnicos y políticos no es como se suele presentar y se presentó en esta ocasión, lo muestran dos situaciones reveladoras: por un lado, el desfase que hubo entre algunas posiciones sostenidas por el presidente de la República, Abel Pacheco, y la posición sostenida por algunos negociadores, concretamente sobre la apertura del monopolio estatal de los seguros y las telecomunicaciones en el TLC. El presidente Pacheco había asegurado en varias ocasiones que estos temas no estaban en la mesa de negociación; sin embargo, fueron negociados.

A este punto, destaca el hecho de que los mismos negociadores formaran parte de una asociación privada denominada "Por Costa Rica", la cual se dedicó a promocionar públicamente la aprobación del TLC. Lo anterior dejó entrever las muestras de interés y la parcialidad que tuvieron desde el inicio en la formulación de la supuesta "posición nacional".

Con lo dicho hasta ahora, queda claro que las implicaciones técnicas y políticas de las decisiones estatales son indisolubles; el peso que tiene cada ámbito depende de la articulación entre la toma de posición de los agentes sociales y sus posiciones de poder en el campo que ocupen.

En relación con lo segundo que se afirmó, que no hay producción de conocimiento, ni siquiera en ámbitos "muy técnicos" como el derecho o la economía, donde no haya disputas, existen algunos ejemplos para evidenciar esa posición, pues si bien compartir la misma disciplina de estudio asegura un lenguaje técnico común, no garantiza pertenecer a una misma comunidad o compartir un paradigma; esto en el sentido que lo plantea Kuhn (1971) y como recuerda Peter Hall (1993).

En el campo de la economía y a propósito de la discusión sobre el TLC en el ámbito nacional, se manifestaron distintos enfoques sobre la visión del desarrollo, con respecto a la importancia del mercado interno en el sector exportador, entre otros aspectos. 
En tanto que, en el caso del derecho, las disputas no fueron menores y hasta dieron origen a nuevas organizaciones, tal como la Asociación para el Estudio Jurídico del TLC (Ase-TLC), ${ }^{14}$ la cual manifestó su criterio discordante con el documento de la Comisión Especial sobre Roces Constitucionales del TLC. ${ }^{15}$ Esta última estuvo conformada por la Rectoría de la Universidad de Costa Rica para tales efectos. Si el tratado requería o no un voto de la mayoría calificada para su aprobación en la Asamblea Legislativa fue también objeto de disputas entre especialistas.

Las divergencias fueron tales que llevaron a la misma jefa del equipo negociador a reconocer "que no existe un único criterio jurídico en relación con muchos de los temas discutidos" e instó al Colegio de abogados a publicar los documentos generados en uno de los talleres de discusión que hubo al respecto, no sin dejar de señalar que de esa forma el Colegio contribuiría con la función que le atribuye la ley: "promover el progreso de la Ciencia del Derecho" (Agüero et al., 2007). ${ }^{16}$

\section{Conclusiones}

Esta investigación partió de dos supuestos. Por un lado, el TLC con Estados Unidos, más que un tratado comercial específico, es una política comercial y de desarrollo de largo plazo y puede ser estudiado como tal. Por otro lado, los negociadores se convirtieron en actores claves de la negociación del acuerdo comercial; esto no solo porque los ministerios son aparatos del Estado que ostentan una posición privilegiada para la creación de las normas y los reglamentos de un área específica, sino también por la función simbólica que ese mismo lugar institucional les confiere.

Desde el punto de vista del tipo de política gestionada, se puede decir que el TLC con Estados Unidos fue la política económica de mayor envergadura que se haya negociado desde que se concertaron los programas del ajuste estructural. Su negociación se hizo de una forma estratégica, puesto que, por un lado, se formuló y se negoció dentro de un área de política muy específica, la de comercio exterior, y, por otro lado, se trató de un acuerdo comercial que involucró gran cantidad de nuevas legislaciones en temáticas muy diversas.

Vale recordar que, a pesar de que la jefa del equipo negociador insistió en señalar que se trataba de un acuerdo comercial similar a los otros siete que se habían firmado y que este solo regulaba asuntos comerciales, el TLC incluyó temáticas no visualizadas hasta entonces en el país, por ejemplo, la propiedad intelectual relacionada con la biodiversidad o el tema de servicios en telecomunicaciones.

En resumen, el TLC constituye una profundización de las políticas económicas adoptadas a mediados de la década de los ochenta, con los programas de ajuste estructural y los préstamos adquiridos para ese efecto. En esa línea, otro analista afirmó que el TLC fue un instrumento para la consolidación de los cambios en el estilo de desarrollo (Rovira, 2004) impulsados desde la mitad de la década de los ochenta. 
Siguiendo lo planteado por Raventós (1995), quien visualizó al equipo del ajuste como parte de una comunidad epistémica afín a los planteamientos del llamado Consenso de Washington, se concluye que en el caso del equipo negociador del TLC hay una continuidad ideológica con esos planteamientos, en lo que a desmantelamiento del proteccionismo y la desgravación arancelaria se refiere.

Cabe decir que la influencia creciente de comunidades epistémicas está relacionada con el proceso de especialización y profesionalización, el cual, a su vez, impacta los saberes estatales en diversas direcciones. Adler y Haas documentaron el impacto de comunidades epistémicas diferentes y plantearon la creación de un programa de investigación reflexivo alrededor de este concepto de "comunidades epistémicas". Ambos autores editaron un libro en el que sistematizaron las experiencias de comunidades en el campo de los servicios, en la lucha por el control de las armas nucleares y diversas luchas de defensa ambientalista, entre otros (Adler y Haas, 1992). ${ }^{17}$

La conformación del equipo estudiado en este trabajo constituye un fenómeno inédito en el país, asimilable parcialmente con el ascenso reciente de las elites tecnocráticas que describe la literatura mexicana o suramericana sobre el tema de política pública (Ai Camp, 1997; Montecinos, 1997; Schneider, 1997).

Los negociadores, ante la disyuntiva entre saberes cosmopolitas y saberes de la cultura política tradicional, optaron por los primeros. Lo anterior debido a la afinidad ideológica con los negociadores y representantes de los organismos internacionales que promovieron el acuerdo comercial con Estados Unidos. Varios mecanismos de socialización profesional permiten entender la forma a través de la cual se construyó esa afinidad.

Siguiendo a Robert Merton (1949), se puede decir que ellos fueron parte de procesos de socialización anticipatoria, al adoptar en forma temprana no solo una serie de normas, valores y creencias, sino también determinados paradigmas sobre el comercio exterior. A continuación se mencionan los mecanismos identificados.

En primer lugar, la adopción de una disciplina determinada y de un área de especialización donde se deposita una expectativa de estatus y de realización profesional.

En segundo lugar, compartir una racionalidad técnica, ya como un medio para la profesionalización de un saber-hacer, ya para resolver problemas en una área específica; o bien, para gozar del estatus simbólico y la legitimidad que da hablar y actuar a partir de las credenciales de la profesión.

En tercer lugar, las relaciones que se establecen, fuera y dentro del país, a propósito de los estudios de posgrado y especialización; una selección temática en la cual tienen un peso importante las relaciones de mentor-aprendiz. Estas se constituyen como funciones de identificación y modelaje a partir de personas consagradas en un campo del saber y a las cuales se opta generalmente por afecto, respeto y admiración de los jóvenes negociadores. En ese sentido, se analizaron dos casos: la influencia de Eduardo Lizano sobre la jefa del equipo negociador, Anabel González, en materia 
del TLC con Estados Unidos; y la influencia de ella como parte del equipo asesor en las tesis de licenciatura y maestría de tres negociadores.

Las publicaciones y los trabajos de graduación de los negociadores muestran que sus ideas a favor de la liberalización comercial formaron parte de su proceso de socialización académica, especialmente en sus estudios de posgrado. Posteriormente, estas se fortalecieron mediante las interacciones con otras instancias académicas privadas e igualmente por medio de experiencia en COMEX.

En cuarto lugar, la interacción con individuos determinados y la existencia de instituciones y espacios de encuentro y promoción de ideas. En el ámbito nacional, hay que mencionar al menos el papel que han jugado dos instituciones académicas privadas: la Academia de Centroamérica y el INCAE, instancias formativas y generadoras de fuentes de trabajo profesional.

En quinto lugar, la formación recibida en el mismo ejercicio del trabajo profesional les generó una experiencia que en muchos casos se vio complementada con pasantías, cursos cortos y una serie de seminarios en los cuales aprendieron o profundizaron saberes específicos. Por ejemplo, las capacitaciones en técnicas de negociación o en los contenidos propuestos en el marco de la OMC. Además, las empresas y organismos internacionales producen sus propias formas de certificación y credenciales, las cuales permiten crear especializaciones de hecho, a partir de las necesidades de los mismos contratantes.

\section{Notas}

1 La idea de un TLC había sido planteada públicamente por los presidentes centroamericanos, en mayo de 1997, ante el presidente Bill Clinton, a propósito de su visita a Costa Rica para participar en la III Cumbre de Presidentes del Istmo, con motivo de la creación del ALCA. Esto ocurrió durante la administración de Figueres Olsen (1994-1998), en Costa Rica, pero no fructificó la propuesta.

2 Autoridad de Promoción Comercial o vía rápida requerida para agilizar las negociaciones comerciales.

En palabras del autor se entiende que "El capital social es la suma de los recursos, actuales o potenciales, correspondientes a un individuo o grupo, en virtud de que éstos poseen una red duradera de relaciones, conocimientos y reconocimientos mutuos más o menos institucionalizados, esto es, la suma de los capitales y poderes que, semejante red permite movilizar" (Bourdieu, 1992, 82).

Básicamente en universidades públicas costarricenses, a excepción de Federico Valerio, quien es egresado de una universidad privada.

Este sería el caso de la jefa del equipo negociador Anabel González y del jefe de negociación sobre inversiones, Federico Valerio, o bien, de la encargada del tema laboral y ambiental Gabriela Llobet. 
Las trayectorias laborales están determinadas por la gestión del empleo que hacen los agentes sociales y para visualizar se trataron de identificar las estrategias seguidas por los negociadores usando la palabra estrategia "para designar las líneas de acción objetivamente orientadas que los agentes sociales construyen sin cesar en la práctica y que se definen en el encuentro entre el habitus y una coyuntura particular del campo; lo cual despoja de sentido a la cuestión de la conciencia o la inconsciencia de las estrategias y, por tanto de la buena fe o del cinismo de los agentes" (Bourdieu, 1992, 89).

Su visión del Estado está relacionada con su visión del poder político y simbólico como algo diseminado en todos los campos de la sociedad y, por lo tanto, su interés de contrarrestar la imagen del Estado más difundida, con la de un ente que monopoliza la lucha simbólica. El autor reconoce que el Estado es objeto de la lucha política en la medida en que este mismo establece las reglas y los procedimientos que definen las relaciones de fuerza del campo de poder. Según el autor: "El campo de poder es un campo definido en su estructura por el balance de la relación entre formas de poder o de tipos de capital diferentes. Es también, simultáneamente, un campo de luchas por el poder, entre quienes detentan poderes diferentes, un espacio de juego donde los agentes y las instituciones que tienen en común poseer una cantidad específica de capital (económico o cultural especialmente) suficiente para ocupar las posiciones dominantes en el seno de sus campos respectivos, se enfrentan con las estrategias destinadas a conservar o a transformar esa relación de fuerzas" (Bourdieu, 1989, 375).

Sin olvidar la participación influyente de economistas de varias generaciones vinculados con la política con pensamiento e inclinación liberal, tal es el caso de Eduardo Lizano, Miguel Ángel Rodríguez y Andrés Rodríguez.

Frente a las críticas del sector productivo, se creó desde el inicio del proceso un mecanismo de relación y comunicación con la sociedad civil, el cual se le encomendó a Amparo Pacheco, directora del Departamento de Aplicación de Acuerdos Comerciales (El Financiero, 21 de diciembre de 2003).

Un ejemplo al respecto fue el papel que jugó el Centro de Estudios para los Problemas Nacionales (CEPN), a finales de los años treinta e inicios de los cuarenta en el siglo pasado, y concretamente el papel que jugó Rodrigo Facio Brenes (1917-1961) en la redacción de la Constituyente de 1949 y, posteriormente, en las políticas de desarrollo nacional.

11 Por neutralidad valorativa se entiende la separación de esferas que, según Max Weber, existe entre los hechos y las valoraciones de estos. Los problemas relacionados con los hechos, la determinación de contenidos lógicos y matemáticos o la estructura interna de los fenómenos culturales, es distinta de la respuesta a la pregunta por el valor de la cultura y de sus contenidos concretos, y sobre dicho valor es que se centra el comportamiento en la comunidad cultural y en las asociaciones políticas (Weber, 1967: 212-213).

12 Respuesta de Fernando Ocampo, a fines de la administración de Miguel Ángel Rodríguez (1998-2002), cuando fue interpelado por un periodista con la siguiente pregunta: ¿qué pasará en la próxima administración con este experimentado equipo de negociación? Él argumentó que esa era una pregunta para los precandidatos, "no para nosotros" y agregó la frase citada más arriba.

Cabe mencionar también que Rosales (1996) analizó el conflicto bananero suscitado entre Costa Rica y la Unión Europea por la restricción de las cuotas bananeras, en el periodo 1992-1994. El autor destacó que en esa ocasión el equipo de asesores y negociadores de la Dirección de Negociaciones Comerciales Internacionales, dirigido por Anabel González, 
se distinguió por su amplio conocimiento técnico en comercio internacional y que "prácticamente, ninguno de ellos -con excepción de Francisco Chacón, actual Viceministro de Comercio Exterior, tenían una amplia experiencia de carrera político-partidista". Este reconocimiento al equipo en términos de conocimiento técnico fue recalcado por Amparo Pacheco, funcionaria del COMEX, durante las entrevistas de esa misma investigación (Rosales, 1996, 105).

Esta asociación, conformada por cerca de 50 abogados, surgió, según se dijo, frente a la desinformación del país en torno al TLC; se manifestó a favor de este y se configuró como "una asociación sin fines de lucro, ni distingo político, cuyo propósito es promover una discusión jurídica seria del Tratado" (Anabel González, Al Día, 24 de marzo de 2005).

Documento "Respuesta a los supuestos roces constitucionales del TLC planteados por asesores de la Rectoría de la UCR" (Ase-TLC, mayo 2007). Participaron en la elaboración del documento: Esteban Agüero, Alejandra Aguilar, Irene Arguedas, Francisco Chacón Bravo, Francisco Chacón González, Marianela Arias, Roberto Echandi, Luis Adolfo Fernández, Neftalí Garro, Gustavo Guillén, Rubén Hernández Valle, Vicente Lines, Aldo Milano, Fernando Ocampo, Luis Ortiz, Alejandro Pignataro, Eric Scharf, Ronald Saborío, Edgar Tenorio, Alan Thompson, Nelly Vargas, Manuel Ventura y Fabián Volio.

La Junta Directiva del Colegio de Abogados publicó un acuerdo en el que indicó que se requería la mayoría calificada para la aprobación del Tratado. Ante las molestias expresadas por algunos de sus miembros, dos meses después llevó a cabo un taller donde se analizaron también otros temas como la relación entre el Tratado y la Constitución Política, el rompimiento de monopolios, la contratación pública, la propiedad intelectual, los temas laboral y ambiental (Al Día, 4 de noviembre de 2004).

Mientras para Bourdieu (1992) el habitus responde a procesos colectivos no asimilables directamente con la intencionalidad individual, para Adler y Haas (1992) las comunidades epistémicas responden a procesos de cooperación basadas en racionalidades instrumentarles. Una reflexión crítica sobre los límites y alcances de este concepto se encuentra en Molina (2009).

\section{Bibliografía}

Adler, Emmanuel y Hass, Peter. “Conclusion: Epistemic Communities, World Order, and the Creation of a Reflective Research Program". Knowledge, Power, and International Policy Coordination. Peter Haas (Ed.), South Carolina, Estados Unidos: University of South Carolina Press, 1992.

Agüero, Esteban et al. "Respuesta a los supuestos roces constitucionales del TLC planteados por asesores de la Rectoría de la UCR". Documento de la Asociación para el estudio jurídico del TLC (Ase-TLC), 2007.

Ai Camp, Roderic. "Tecnocracia a la mexicana, ¿antecedente a la democracia?". Pensamiento Iberoamericano, Revista de Economía Política, (30), 1997, pp. 154-176.

Alonso, Eduardo. Evolución del Intercambio comercial de Costa Rica. Programa Estado de la Nación, 2009. Informe Final de ponencia presentada para el Decimoquinto Informe Estado de la Nación en Desarrollo Humano Sostenible. San José, Programa Estado de la Nación. 
Arias Sánchez, Óscar. Grupos de Presión en Costa Rica. San José, Costa Rica: Editorial Costa Rica, 1974.

Barquero, Marvin. “Entrevista: Roberto Echandi G”. La Nación. 21, julio, 2008. Recuperado de http://www.nacion.com/economia/Entrevista-Roberto-Echandi_0_989901131.html

Bermúdez, Kattia. “Quiénes negocian el TLC?”. El Financiero. 25, marzo, 2001. Recuperado de http://wvw.elfinancierocr.com/ef_archivo/2001/marzo/25/informe16.html

Bermúdez, Kattia. “Confío en el poder de las ideas". El Financiero. 3, enero, 1999. Recuperado de http://wvw.elfinancierocr.com/ef_archivo/1999/enero/03/informe3.html

Bourdieu, Pierre y Wacquant, J. D. Respuestas por una antropología reflexiva. México: Grijalbo, 1992.

Bourdieu, Pierre. El sentido práctico. Buenos Aires: Siglo XXI Editores, 2007.

Bourdieu, Pierre. La Noblesse d'Etat. Grandes ecoles et esprits de corps. París: Minuit, 1989.

Camou, Antonio. "Los consejeros del príncipe. Saber técnico y política en los procesos de reforma económica en América Latina". En Nueva Sociedad, (152), 54-67, 1997.

Coller, Xavier. Cuadernos Metodológicos \# 30. Madrid, España: Centro de Investigaciones Sociológicas, 2005.

COMEX. Tratado de Libre Comercio entre Centroamérica y Estados Unidos: Posición Nacional. San José, Costa Rica: Ministerio de Comercio Exterior de Costa Rica, 2003. Recuperado de http://www.comex.go.cr/negociaciones/usa/publicaciones/default.asp

Dezalay, Yves y Garth, Bryant. The internationalization of Palace Wars. Lawyers, Economist, and the Contest to Transform Latin American States. Chicago, Ill., Estados Unidos: The University of Chicago Press, 2002a.

Doryan, Eduardo. De la abolición del Ejército al Premio Nobel de la Paz. San José, Costa Rica: Editorial de la Universidad de Costa Rica, 1990.

Dubar, Claude. La socialization. Construction des identitiés socials et professionnelles. París: Armand Colin Editeur, 1991.

Echandi, Roberto et al. La Ronda de Uruguay y el fortalecimiento del Sistema Multilateral de Comercio del GATT. San José, Costa Rica: Seminario de Graduación para optar por el título de Licenciado en Derecho de la Universidad de Costa Rica, 1991.

Jiménez, Yuri Lorena. “La sencillez y la constancia". La Nación. 8, febrero, 2004. Recuperado de http://wvw.nacion.com/dominical/2004/febrero/08/dominical8.html

Khun, Thomas. La estructura de las revoluciones cientificas. México: Fondo de Cultura Económica, 1971.

Lahire, Bernard. El espíritu sociológico. Buenos Aires: Ediciones Manantial, 2006.

Lizano Fait, Eduardo y González Vega, Claudio. Documento No. 4. La política de comercio exterior de Costa Rica. San José, Costa Rica: Academia de Centroamérica, 2001.

Llobet, Gabriela. Las regulaciones ambientales contenidas en el Tratado de Libre Comercio de América del Norte. San José, Costa Rica: Tesis de Licenciatura en Derecho por la Universidad de Costa Rica, 1995.

Martínez, Juliana. Participación ciudadana e implicaciones para la democracia. TLC con Estados Unidos. Contribuciones al debate. ¿Debe Costa Rica aprobarlo? María Flores y Gerardo Hernández (Ed.). San José, Costa Rica: Instituto de Investigaciones Sociales de la Universidad de Costa Rica, 2004, pp. 37-58.

Merton, Robert. Teoría y estructura sociales. México: Fondo de Cultura Económica, 1949. 
Molina, Eugenia. “Estrategias de socialización profesional y política pública: El caso del equipo negociador del TLC con Estados Unidos". Tesis doctoral, Facultad Latinoamericana de Ciencias Sociales, Guatemala, 2009. Impreso.

Montecinos, Verónica. "Los economistas en la política de partido. La democracia chilena en la era de los mercados". Pensamiento Iberoamericano. Revista de Economía Política, (30), 1997, pp. 135-154.

Ocampo, Fernando y Madrigal, Luis A. El Sistema Nacional de Comercio Exterior. San José, Costa Rica: Licenciatura en Derecho de la Universidad de Costa Rica, 1993.

Parsons, Talcott. La estructura de la acción social. Tomo 1 y 2. Madrid: Ediciones Guadarrama, 1961. Pérez, Juan Pablo, Andrade-Eekhoff, Katharine, Bastos, Santiago y Herradora, Michael. Centroamérica durante la década de los 90. San José: FLACSO/CEPAL, 2004.

Raventós, Ciska. "De la imposición de los organismos internacionales al "ajuste a la tica". Nacionalización de las políticas de ajuste en Costa Rica en la década de los años ochenta". Revista de Ciencias Sociales, (76), 1997.

Raventós, Ciska. "The Construction of an Order: Structural Adjustment in Costa Rica (19851995)". Tesis doctoral, New School for Social Research de New York, 1995. Impreso.

Robinson, William. "Social Theory and Globalization: The Rise of a Transnational State". Theory and Society, vol. 30, n. ${ }^{\circ}$ 2, 2001, pp. 157-200.

Rosales V., Rotsay. El proceso de toma de desiciones en la politica exterior-comercial de Costa Rica en el conflicto bananero (1992-1994). Tesis de Maestría en Ciencias Políticas. San José, Costa Rica: Universidad de Costa Rica, 1996.

Rovira Mas, Jorge. “Ciencia social y valores en Max Weber". Revista de Ciencias Sociales, (103104), 127-142, 2004a.

Rovira Mas, Jorge. "El nuevo estilo nacional de desarrollo de Costa Rica y el TLC". En María Florez-Estrada y Gerardo Hernández (Eds.), TLC con Estados Unidos. Contribuciones para el debate. ¿Debe Costa Rica aprobarlo? San José, Costa Rica: Instituto de Investigaciones Sociales de la Universidad de Costa Rica, pp. 309-346, 2004 b.

Schneider, Aaron. La construcción del Estado y los regímenes fiscales en Centroamérica. Guatemala: F y G Editores, 2014.

Schneider, Ben Ross. "Las bases materiales de la tecnocracia: La confianza de los inversionistas y el neoliberalismo en América Latina". Pensamiento Iberoamericano. Revista de Economía Política, (30), 1997, pp. 109-132.

Valerio de Ford, Federico. Costa Rica, el banano y la Comunidad Europea. San José, Costa Rica: Trabajo Final de Graduación en el Instituto del Servicio Exterior Manuel María Peralta del Ministerio de Relaciones Exteriores y Culto del Gobierno de Costa Rica, 1993.

Weber, Max. Economía y Sociedad. México: Fondo de Cultura Económica, 1964.

Weber, Max. El político y el científico. Madrid: Alianza Editorial, 1967.

Eugenia Molina Alfaro. Costarricense, graduada del bachillerato y la maestría en sociología de la Universidad de Costa Rica en 1985 y 1990, respectivamente. Obtuvo su doctorado en Ciencias Sociales, en el Programa Centroamericano de Posgrado de Flacso Guatemala en el año 2009. Se desempeñó como investigadora del Instituto de Investigaciones Sociales de la Universidad de Costa Rica en el periodo 2000-2005 
y actualmente es profesora e investigadora de la Escuela de Sociología de la misma universidad. En esa unidad académica coordinó el Eje Metodológico de la carrera en el periodo 2009-2012 y actualmente coordina la Comisión de Investigación y Acción Social. Imparte el curso de Sociología del Estado desde el año 2015 así como el Seminario de extensión docente titulado "Elites profesionales y políticas públicas 2013-2014". Es autora de varios artículos sobre temas de políticas, desarrollo y desarrollo local, asimismo, ha sido responsable de proyectos de investigación sobre dichos temas.

Contacto: molina.eugenia@gmail.com 
